\title{
Integrated policy formulation processes in local governments: A case study in mid-western Uganda
}

David Mwesigwa $^{1 *}$, Mohammed Bogere ${ }^{2}$, Lina Anastassova ${ }^{3}$

Discipline of Public Administration and Management, Lira University, Lira, Uganda ${ }^{1 *}$

Discipline of Public Administration and Political Studies, Nkumba University, Entebbe, Uganda ${ }^{2}$

Faculty of Business Studies, Burgas Free University, Burgas, Bulgaria ${ }^{3}$

mwesigwadavid22@gmail.com

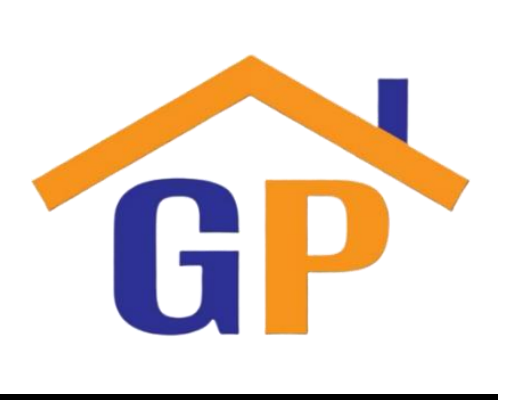

Article History

Received on 7 May 2021

Revised on 27 May 2021

Accepted on 10 June 2021

\begin{abstract}
Purpose: This study set out to assess the level of policy formulation in Hoima district local government for effective service delivery in Uganda.
\end{abstract}

Research methodology: A quantitative case study design was embraced, aiming at 30 local councillors and 60 technical officials. The real sample was 54 respondents. Data were gathered via a selfadministered questionnaire and an interview guide. Numerical and non-numerical data were examined by way of descriptive statistics as well as thematic analysis.

Results: Results suggest a moderate mean for policy formulation in Hoima as generated from all the five constructs namely; problem identification $(\mu=2.88 ; \mathrm{SD}=1.346)$, problem manifesto $(\mu=2.76 ; \mathrm{SD}$ $=1.347)$, policy agenda $(\mu=2.17 ; \mathrm{SD}=1.268)$, policy debate $(\mu=2.58 ; \mathrm{SD}=1.271)$ and policy decision $(\mu=2.20 ; \mathrm{SD}=1.268)$. This was so because the overall mean was 2.52 and the overall SD was 1.300. Nevertheless, the numerous impediments confronted mainly at policy decision disrupted the process.

Limitations: The study concentrated on one local government in Uganda and so the results may not be generalised to Uganda.

Contribution: These results might be used as contributions for local governments in Uganda to evolve a guide on integrating policy formulation issues during orientation and or retooling local councillors and technical officials for better policy formulation processes. This article contributes to the budding understanding by underlining undertones in policy formulation so that local governments become more efficient in delivering services to the citizenry.

Keywords: Policy, Policy formulation, Council, Councillors, Technical official

How to cite: Mwesigwa, D., Bogere, M., \& Anastassova, L. (2021). Integrated policy formulation processes in local governments: A case study in mid-western Uganda. Journal of Governance and Accountability Studies, 1(2), 83-101.

\section{Introduction}

Policy formulation is an act of developing rules and guidelines that ensure the organisation's smooth running of activities to allow an organisation to achieve its objectives (Stark \& Head, 2019). It is broadly a proposed course of action of an individual, group, institution, or government to realise a specific purpose within a given environment (Bhuiyan \& Farazmand, 2020). Public policy is described as anything government chooses to do or not to do with the understanding that public policies involve a fundamental choice, on the part of the government, to do something or do nothing (Vesely, 2020). 
Moreover, public policy refers to a set of interrelated decisions taken by a political actor, or groups of actors, conceiving the selection of goals and means of achieving them within a specific situation and, where such decisions should be within the authority of those entrusted (Kuttig, 2020).

At its most simple level, a public policy is a choice made by the government to undertake some action. Preference, here, is given to the government's capacity to implement its decisions as a significant consideration in the types of decisions it takes. Although that study addresses institutions, it appears to denote that policy formulation is about whatever governments or other institutions choose to do. According to Colzin (2020), it is about selecting goals and means of achieving them. Mortati (2019) reveals that policy formulation involves a fundamental choice of government to do something or nothing. According to Saraithong and Chancharcoenchai (2019), it involves a course of action to realise specific objectives within a given environment. This suggests that a public policy is a purposive course followed by an actor or a set of actors in dealing with a problem on matters of public concern. This factor points to policy decisions often taken by sets of actors rather than a sole actor within a government. Policies are often a result of not only multiple decisions but of multiple decisions taken by multiple decision-makers within complex organisations.

In this view, the link between three issues is underlined: government action and the perception of the existence of a problem requiring actions within their limitations. Indeed, public policy cannot be accomplished by going through the official records of government, such as laws, regulations, and promulgations (Chijioke-Oforji, 2019). According to Ng, Mohamad, Chandran and Noor (2019), the nature of public policy has three attributes, namely; i) a public policy has different interpretations; ii) it may be narrow, concerning a specific activity, and iii) it may be applied to all people in a country, or limited to a section of the population. In their study, Capano, Howlett and Ramesh (2015) maintain the view that government may have specific policies and, in that case, there will be 'mega policies', which are general guidelines to be followed when implementing specific policies. Mega policies involve establishing oriented goals to serve as guidelines for the larger sets of concrete and specific policy (Mwesigwa \& Mubangizi, 2015). Hence, every policy should contain specific goals in more precise or understood terms (Natiyi, Santoro, Giuliani \& Mazzetti, 2020). ) as a consequence, public policies in modern political systems, are goal-oriented constructs; they may either be positive or negative in form. In its positive form, the public policy can involve some form of obvious government action to deal with a particular problem. In its negative form, policy involves a decision by public servants not to take action concerning a matter on which government order is required. Boossabong and Chamchong (2019) reveal that public policy is based on law and commands the objectives of citizens. Thus, the policy has a legally coercive feature that citizens accept as legitimate and distinguishes public organisations different from non-public organisations.

\section{Literature review and hypothesis development}

\subsection{The systems view of policy formulation}

The systems view presents the policy formulation process from the view of a 'black-box' that converts a particular society's demands into policies (Pan, Li, Xu, Guo, Guo \& Lee, 2020). This model uses the political structure, involving inputs, demands, the environment and supports, to analyse the policy formulation process.

\subsubsection{Inputs}

These are the physical, socioeconomic and political resources in the environment, which are received into the political structure in the form of both demands and supports (Vercalsteren, Christis, Geerken \& Van Der Linden, 2020). Looking at the systems model, a set of four assumptions is generated: The systems model assumes that every citizen has access to resources for contributing, oblivious of the fact that a number of citizens in less-developed countries bring nothing physical into the political system except for votes. The social resources involve values and attitudes, which cannot be expected in modern political systems due to the constant relocations as well as employment of outsiders into LG management. Consequently, many technical personnel in LGs may not be native, so they may not bring useful values and attitudes into the political system. The economic resources include financial contributions made in the form of taxes. So, the political system is likely to be overtaken by events since 
the most popular taxes have been suspended by governments in a number of developing countries. This leaves LGs with no reliable source of revenue to support the political system. A number of citizens contribute political proposals, such as policy expectations, to the political system (Frisk \& Gillette, 2019); these are inadequate without physical and socioeconomic supports.

\subsubsection{Demands}

These are claims made on the political system by individuals and groups to adjust certain aspects of the environment. According to the systems model, demands are 'even' when individuals or groups act to effect public policy. The model offers a non-universal outlook devoid of the view that few individuals and groups make decisive demands on the political system (Mwesigwa \& Mubangizi, 2015). This way, making demands calls for certain means of citizen participation, which are rarely present or allowed by central government agencies to the claimants. Hence, it is clear that a number of local citizens lack adequate means to make substantial claims and there are few local activists whose influence on the political system is inconsequential.

\subsubsection{The environment}

This is any condition or event defined as external to the boundaries of the political system. The supports of a political system should be conscious of the rules, laws, and customs that provide a basis for a community and the authorities (Carbone \& Farina, 2020). Yet, LGs' policy formulation is not as effective as it should owing to:

(i) The dominion imposed by the central government machinery on the process;

(ii) The difficulty of interpreting laws, especially those made by the national parliament, for example, local councillors whose formal education is very low; and

(iii) A number of customs being are too rigid to foster inter-cultural relations.

\subsubsection{Supports}

These are the non-quantifiable and or quantifiable inputs into a political system, such as obeying laws or patriotism, which constitute psychological and or material resources of the system (Spéder, Murinkö \& Oláh, 2020). Obeying laws calls for three basic considerations:

(i) Democracy in the sense that laws were made by and adopted through a democratic process;

(ii) Rule of law, which does not discriminate in favour of or against anyone on the basis of any socioeconomic or political factor; and

(iii) Citizens that respect faith in the laws with the hope that justice will be seen to be done. Hitherto, conditions reveal that, while existing laws may have been made representatively, the notion of rule of law, respect for and faith in the same laws is a challenge.

\subsection{The institution and personnel in the process of policy formulation}

The systems model suggests that there is a policy and or policies that is/are depicted as an output of the political system. For example, LGs are symbolic of the peoples' institution for policy formulation, elected by the majority (Durrer, Gilmore \& Stevenson, 2019). However, both the elected and appointed officials within these structures may not represent the outcome of the political system. This could be due to the fact that there are rare opportunities for the electorate to interface with their leaders in order to make proposals and get feedback regarding the policy outputs.

\section{Feedback}

In policy formulation, feedback focuses on the policy outcomes regarding the problem that was defined. Feedback shows that policies have a change outcome on the environment and the demands. The notion of feedback is demonstrated under the institutional structure and personnel in policy formulation to be affected by the gap between the electorate and the leaders (He, Ratigan \& Qian, 2020). Per se, the policies formulated may lack an appropriate effect on the character of the political system. Hence, the systems model calls for consideration of six consequences, which can enhance the policy formulation process:

(i) The significant dimensions of the LG environment that generate demands upon the political system by looking at the ability of councillors to deal with the complexities of policy formulation. 
(ii) The key characteristics of the LG political system, which facilitate it to transform the demands of the people into public policy and to preserve itself over time.

(iii) The effect of the district environmental input such as taxes and opinions on the character of the political system.

(iv) The characteristics of the LG political system on the content of public policy formulation.

(v) The outcome of environmental inputs on the content of public policy.

(vi) The outcome of public policy, in form of feedback from the local community and other decisive citizens such as civil society, the socioeconomic and political environment of the LG and the character of the political system.

As a remedy, the systems model presents a set of four issues in the policy formulation process, viz.:

(i) Policy formulation is a technique used to measure organisational effectiveness by evaluating the effect of a programme. Thus, policy formulation involves estimating the impact of the policy on the local programmes and projects.

(ii) It is a systematic and data-based alternative to intuitive ideas about the effects of policy options used in problem assessment and monitoring as a 'before-the-view' decision tool.

(iii) It puts data to use in deciding about, estimating and measuring the consequences of public policies, such as whether any new district should be carved out of an existing district (Siverbo, Cäker \& Åkensson, 2019). And,

(iv) It provides maximum ideas with minimal costs about the likely consequences of proposed policies, the actual consequences of the policies in place, and various approaches to be applied to implement or assess them, i.e. cost-benefit analysis.

According to the systems model, policy formulation involves five stages: identifying the problem and making the policy choice (Burke, 2019).

Stage one - Identification of the problem, which is concerned with determining whether and why a problem is crucial, i.e. defining the problem involves moving from ordinary descriptions to a more abstract, conceptual plan.

Stage two - Determining options for the policy choice, which involves determining the alternative courses of action in order to decide which kind of intervention is most positive in any particular situation.

Stage three - Forecasting the policy consequences, which concerns itself with determining the consequences of each of the alternatives for policy choice as well as predicting all the effects of the proposed policy.

Stage four - Forecasting the policy outcomes, which presupposes recommending a policy decision by evaluating the possible level of improvement.

Stage five - Making the Policy Choice, which is interested in coming up with the final policy. The situation may be so simple for the policy-maker that they can simply look at the consequences predicted in each alternative and select the one that is best, or it may be so complex that one will have to think of their preferences.

Thus, policy formulation is an important process since knowledge and scientific analysis are always better than the absence of any knowledge. Policy formulation rests on the assumption that information is better than no information, and right questions are better than no questions asked, even when the answers may not be definite. Even though policy analysis may not provide solutions to every society's challenge, it is an appropriate tool for approaching policy questions (Bartels, Wagenaar \& Li, 2020). This way, it facilitates us to describe and explain the causes and consequences of problems affecting a broader society.

\subsection{The rational model of policy formulation}

The rational model is based on the principle of prudence, which highlights that policy formulation consists of making a choice among alternatives on reasonably qualified grounds (Reed, Curtis \& Lovrich Jr. 2020). Since prudence aims 'to choose the one best option'; a policy is rational when it is the most efficient (Saxon \& Snow, 2020). Consequently, if the ratio between the values a policy achieves and the values it sacrifices is positive and higher than any other alternatives, it is a good policy 
(Horodnic \& Williams, 2019). Essentially, this model involves the calculation of every social and economic value sacrificed or achieved by a policy. Thus, policy-makers should be rational by assessing each of the four stages, i.e.:

Stage 1 - Identifying and determining the goals by ascertaining a wild set of goals that need to be realised through the projected policy.

Stage 2 - Ranking of goals in order of importance regarding the proposed policy.

Stage 3 - Identification of possible policy alternatives by outlining the options that are likely to achieve the set goals.

Stage 4 - The cost-benefit analysis of policy alternatives expected to accrue from the policy.

The central requirements to policy-makers who choose to select the rational model include:

(i) Knowledge of all society's value preferences and their relative weights;

(ii) Knowledge of all policy alternatives available; knowledge of all the consequences of each policy alternative;

(iii) Calculating the ratio of achieved to sacrificed societal values for each policy alternative; and

(iv) Selecting the most efficient policy alternatives (Awin, 2019).

Rational policy-making requires making firm choices among different alternatives. Once a choice is implemented, the policy-maker is required to monitor its implementation to observe the accuracy of expertise and estimates of the decision-makers. In a number of LGs in Uganda, rational individuals are hard to come across (Romanowski, Sadiq, Abu-tineh, Ndoye \& Aql, 2019). Consequently, the rational model presents five key constraints to policy-makers:

(a) The accomplishment of goals: Rational policy-making is a very demanding exercise since by the time the policy-maker recommends a rational policy, the problem in question has already become very complex (Farrell, Bourgeois-Law, Buydens \& Regehr, 2019). This way, rational presentations become decisions made on the basis of societal goals. Also, policy-makers try to maximise their own rewards, such as influence, status, and money, which shifts rational policy from a goal to an exercise.

(b) Securing optimisation: The model is expected to yield optimal outcomes, which it does not and individual interests become more important than public interest (Rucket, Labonté \& Lenchucha, 2019). Therefore, the motivation for policy-makers is to maximise their achievement as they do strive to search until they find the one best alternative.

(c) The conflict between natural choice and need in action: Policy-makers are not motivated to make decisions on the basis of societal goals, but they try to maximise their own reward, such as power; the time involved in realising a thorough analysis of the impending policy may be short during an emergency (Wanders, Dijkstra, Maslowski, Van Der Veen \& Amnå, 2020); and, there are several conflicting values among specific groups and individuals that obstruct policy-makers from making an effective comparison of options.

(d) The tendency of the deliverance of political feasibility: The model is concerned with what is possible; the probability that, however rational a policy option is, it does not mean that it will be acted upon. Politicians often resolve issues by avoiding conflict and often the best action to do nothing because of the possible consequences (Aburgre, 2020). Thus, uncertainty about the consequences of different alternatives can force politicians to cling to previous policies because they do not want to lose popularity.

One of the ultimate problems identified in this study is tracing the distinction between rational power and irrational power. If that distinction is determined, it can mean that citizens have been granted adequate power over policy formulation (Schulz, 2020). For instance, there is little confidence to show that new LGs and urban councils will take power, including policy formulation, closer to the citizens (Musenze \& Sifuna, 2020). The solution to this distrust lies in the participatory policy formulation process, an issue that compares positively with the views of Lourival and Rose (2020), who notes that policy-makers should never be compromised by those who think that they have the upper hand in policy formulation. In Uganda, policy formulation is a preserve of adults (Mwesigwa \& Mubangizi, 2015). At 
LG level, members of the Technical Planning Committee (TPC) often dominate the process; those with relatively more education influence the process in their favour or the desired direction.

\subsection{Positioning policy formulation}

Policy formulation is described as the development of policy alternatives to deal with problems on the public agenda. This occurs in public bureaucracies, interest groups, civil society organisations, legislative committees, and policy planning agencies (Mortati, 2019). The scope of public policy comprises the four sets, viz.: First, national-level policies, where policies related to security, economy, fiscal activities and taxation, are developed for the national good (Hardy, Jakhelln \& Smit, 2020); Second, sectoral policies, which involve sector-specific policies and are located within specific ministries such as agriculture (Schmidt, 2020); Third, operational policies, which involve implementing agencies and government departments deciding their operational policies from policies of the sectors they operate (Grossmann-Wirth, 2019); and, fourth, local-level policies, which embrace the local community and LG institutions at the local level (Burke, 2019). Nonetheless, other policies call for every local policy to be consistent so as to realise the national goals and objectives. It is projected that if policy formulation is effectively dealt with, we would determine the appropriate mechanisms for its enhancement. In the absence of this, citizens are likely to remain in a dilemma regarding what should be done. This study approached policy formulation from five angles: problem identification, policy manifesto, policy agenda, policy debate, and policy decisions.

\subsection{Problem statement}

The process of policy formulation remains key to the effective functioning of local governments in Uganda; however, a wide range of issues appear to impede the progress of a number of local governments arising, in part, from failure to determine current levels so that efforts can be made to either consolidate that level or enhance it. Issues of unproductive problem identification phase in local governments and urban councils leading to inability to address the general needs of the population are rampant. There are several deficiencies in the policy manifesto that do not allow the aggregate of policies from different interest groups to effectively compete with their proposals for district recognition and action coupled with ineffectiveness of the policy agenda to allow citizens to compile the intended activities and profile them, and engage in vigorous debate. Also, signs of deficiencies in policy debate result in failure to have an extensive discussion of the various aspects and dimensions of a policy problem. Consequently, the policy decisions cannot easily be converted into programmes and projects for implementation. As a result, this study aimed to assess the level of policy formulation in one rural local government in mid-western Uganda so that recommendations can be sought to enhance the process.

\section{Research methodology}

The study adopted the quantitative case study design. It was quantitative because the study involved testing a set of variables and analysed them using statistical procedures; the case study was chosen because the problems in this study involved an intensive investigation of the complex factors that contributed to the individuality of a political unit (Assad \& Spiegel, 2020). The case study presents a rural district of Hoima, comprising parts that are town boards and rural sub-counties. In addition, the district is populated by peoples from various parts of Uganda, although the indigenous Banyoro polity constitutes the highest percentage. This, in fact, compares favourably with the ethnic composition of the entire country, which renders it a successful study under the case study design.

\subsection{Area of study}

The study was conducted in Hoima district, mid-western Uganda.

\subsection{Target population}

The study targeted two units of the population, i.e. elected councillors and appointed officials. All the district and sub-county councillors in Hoima district were considered locally elected officials. The study also considered all the appointed staff at the district and sub-county headquarters. The accessible population became the sampled population using Krejcie and Morgan's (1970:608) table. These included: a) a total of 30 councillors; b) 60 technical officials. In essence, out of the 30 elected officials 
selected, $92 \%$ were accessed and out of the 60 technical officials selected, $77 \%$ were accessed. Overall, out of 90 respondents, 63 were accessed. The accessibility generated a proportion of $84 \%$ of the sample. The proportionate stratified sampling technique was used to select the respondents and a simple random sample was generated from each of the two sub-populations. Data were collected using a selfadministered questionnaire and in-depth interviews with key informants. The limitations imposed by the use of the English language were minimised by giving explanations to those respondents who showed any difficulty in understanding the language. Local councillors were more willing respondents (92\%) than technical officials (77\%). Overall, of the required minimum 126 (65\%) SAQs needed, the researcher achieved $161(84 \%)$.

\subsection{Quality control}

The outcomes of three of the five external consults $(75 \%)$ were subjected to content validity tests (CVTs). The outcomes indicated that: a) $35.2 \%$ of all the factors in the questionnaire were very relevant, $39.8 \%$ were relevant, $20.4 \%$ were irrelevant, and $4.6 \%$ were very irrelevant; b) $54.3 \%$ of all factors in the interview guide were very relevant, $28.6 \%$ were relevant, and $17.1 \%$ were irrelevant. By inference, the instruments generated an average CVI as follows: very relevant $(44.7 \%)$, relevant $(35.6 \%)$, irrelevant $(16.7 \%)$ and very irrelevant $(3.0 \%)$. The overall CVI indicates that since the instruments yielded a total of $80.3 \%$ for very relevant and relevant cumulatively, they were treated as valid for data collection after corrections. The outcomes generated from the inter-consult coefficient revealed: a) respondents' profile $(3 / 3=1.0)$; b) policy formulation $(2 / 3=0.6)$; and factors affecting policy formulation $(2 / 3=0.6)$. The overall CVI was that the outcomes of the inter-consult coefficient average for the five scales were $0.76(>0.60)$. Reliability of instruments was attained through pre-tests that were held in an interval of two weeks in Buseruka and Kitoba sub-counties using 13 randomly selected respondents. The outcomes revealed that the instruments were $78 \%$ reliable.

\subsection{Data analysis}

Quantitative data analysis was conducted using the Statistical Package for Social Scientists (SPSS) to establish the level of relationship between the study variables to make sense of the data. As a result, the following strategies were applied: all data were initially analysed by means of frequencies and percentages, and using frequency tables, descriptive statistics were used to generate means $(\mu)$ and standard deviations (SD).

\section{Results and discussions}

Policy formulation was assessed using five factors: problem identification, policy manifesto, policy agenda, policy debate, and policy decisions.

\subsection{Problem identification}

Problem identification was further stretched using a five-construct Likert scale ranging from 1 to 5 , where $1=$ Strongly Disagree, 2=Disagree, 3=Neutral, 4=Agree and 5=Strongly Agree. Data was then analysed using descriptive statistics, as illustrated in table 1.

Table 1. Descriptive statistics on the level of problem identification in the Hoima District

\begin{tabular}{lll}
\hline Constructs & $\boldsymbol{\mu}$ & SD \\
All citizens in the district participate in identifying local needs. & 3.36 & 1.314 \\
Your district relies on the council and executive meetings. & 3.34 & 1.321 \\
Your district conducts workshops in order to generate local needs. & 3.02 & 1.432 \\
Your district uses research reports to identify local priorities. & 2.74 & 1.321 \\
Newspapers are used to generate local needs in your district. & 2.66 & 1.385 \\
Your district has adequate means to generate the people's needs. & 2.84 & 1.344 \\
Your district has enough time to identify all the people's priorities. & 2.22 & 1.305 \\
Average & $\mathbf{2 . 8 8}$ & $\mathbf{1 . 3 4 6}$ \\
\hline
\end{tabular}

Legend: 1.00 - 1.70 (very low), 1.70 - 2.40 (low), 2.40 - 3.10 (moderate), $3.10-3.80$ (high), $3.80-5.00$ (very high)

Source: Primary data. 
Problem identification requires collective citizen participation in order for the $\mathrm{LG}$ to act on the general needs of the population. The different sources of problem identification included: newspapers, research reports, workshops, and meetings. The outcomes reveal that the construct "all citizens in the district participate in identifying local needs", most of the respondents (37\%) agreed though 15\% strongly disagreed $(\mu=3.36 ; \mathrm{SD}=1.314)$; whereas on the construct "the district relies on the council and executive meetings", most of the respondents (29\%) agreed and only $12 \%$ strongly disagreed $(\mu=3.34 ; \mathrm{SD}=1.312)$. The two outcomes were interpreted as "high", thus implying that citizens held the view of participation in the identification of local needs in high regard, thus supporting the outcomes of a study by Mwesigwa and Mubangizi (2015), who found citizen participation to be an essential ingredient in policy formulation. Similar outcomes were generated regarding the construct "reliance on the district council and executive meetings". The outcomes in table 1 further reveal that once people participate in determining their local needs, and the decisions of the district council would be brought into line with the people's judgement. This view resonates with the findings of Panday and Chowdhury (2020) who established success in a number of decentralised projects as a result of popular citizen participation. Regarding reliance on meetings during the policy-making process, one of the key informants noted:

As the technical officials, we hold consultations with local councillors regarding the policy formulation process, especially at the initial stages, because this is very crucial. We engage in the various district planning and budgeting conferences where both technical officials and local councillors raise a range of issues through the bottom-up approach. (Member, Agricultural sector, 08/02/2021)

The outcome suggests more comprehensive consultations between technical officials and local councillors during the problem identification phase. Such consultations between technical officials and local councillors relate to ideas put forward by the disciples of the systems model, who propose that the policy formulation process involves converting the demands of society into policies (Viollet, Scelles \& Ferrand, 2020). Indeed, the systems model presents the political system involving inputs, demands, environment, and support; as such, the success of the four ingredients presented under the systems model call for wider consultations indicated by the key informant in the extract the Hoima district agricultural sector.

All the four constructs concerning problem identification were rated differently. First, concerning the statement "the district conducts workshops in order to generate local needs", most of the respondents (27\%) disagreed while $20 \%$ agreed $(\mu=3.02 ; \mathrm{SD}=1.432)$, interpreted as "moderate". The study considered district workshops as an important forum for identifying 'problems'. The outcome further shows that once members are given the opportunity to have friendly interactions concerning local needs, they are more likely to get involved freely and justly. Second, concerning whether "the district uses research reports to identify local priorities", most of the respondents (30\%) agreed while 20\% disagreed $(\mu=2.74 ; \mathrm{SD}=1.321)$, interpreted as "neutral". The study established the importance of research reports as a secondary source of problem identification. Although the outcome was, for the most part, "middleof-the-road", there were indications that respondents considered the use of research reports as a vital step towards an effective policy formulation process. Third, regarding the factor "newspapers are used to generate local needs in your district", most of the respondents (27\%) disagreed, although $24 \%$ agreed $(\mu=2.66 ; \mathrm{SD}=1.385)$, interpreted as "neutral". This outcome indicated that newspapers were used sparingly during the policy formulation process.

The fourth construct was regarding whether "the district has adequate means to generate the people's needs", most of the respondents (29\%) agreed, although a significant proportion (24\%) strongly disagreed $(\mu=2.84 ; \mathrm{SD}=1.34)$, interpreted as "high". This outcome confirmed that the district had plenty of the means to generate the needs of the people. This outcome, however, left "a lot to be desired" since it contradicted what was argued by one of the key informants, who noted:

Our district does not have sufficient means to generate the needs of the people in Hoima. When anyone claims the opposite, they should be telling lies because me I have been working in this 
district for the last 13 years and I have seen how the policy formulation has been a bet for the most part. (Member, District Planning Unit, 08/02/2021)

The outcome from the key informant suggests that the district did not have sufficient means to generate the needs of the people. Only one statement was rated "low" by the respondents regarding the problem identification, and this was related to whether "the district has enough time to identify all the people's priorities". Most of the respondents (41\%) strongly disagreed and only $13 \%$ agreed $(\mu=2.22$; $\mathrm{SD}=1.305$ ). The outcome indicated that local people's priorities were often neglected as a result of the scarcity of time at the district. This outcome further confirmed that the Hoima district did not have adequate time to deal with all the needs and priorities of the people. As mentioned, the concern of inadequate time was seen to affect the quality of problem identification and directly obstructs policy formulation in the Hoima district. Shortage of time was the only factor that was rated as "low" by the respondents.

The overall picture for all the seven constructs concerning problem identification revealed a mean of 2.88 and an SD of 1.346. On average, the respondents rated problem identification moderately, given its neutral response mode, on the success of policy formulation in the district. Nonetheless, problem identification was not rated as "very high," indicating that the ultimate outcome could not be better than its base. This view agrees with Mortati (2019), whose study found that the existence of policy design was peripheral due to a dearth of formal appreciation or due to a gap in the day-to-day profession or policy makers to involve participants and recognise their desires successfully. During one of the interviews, when a key informant was asked about "how the general needs of the district [were] identified in the district?" she noted that;

[t]he general needs of the population in Hoima district are identified using the different forums that range from parish development committees, sub-county/town council, the municipal council, and the district planning and budgeting conferences. If those in authority would exploit all these forums, then the magnitude of policy formulation in the district would be triumphant. (Member, District TPC, 08/02/2021)

The outcome generated from the interview confirms that the Hoima district had adequate forums for generating local problems ranging from the parish to the district. Nonetheless, it remained the role of the district leadership to exploit the existing opportunities for better problem identification by, especially, dealing with those constructs that were rated as "low" by the respondents. They include allocating more time to identify all the people's priorities, allowing civil society to invite influential officials to policy conferences, or engaging in vigorous discussions about LG activities.

\subsection{Policy manifesto}

In this study, the policy manifesto involved three key activities, namely: the screening of aggregate policies from different interest groups; interests groups competing on the basis of their manifestos for government recognition and action; the publishing of policy positions; and inviting influential government officials to functions as a way of lobbying. Table 2 presents the outcomes generated from the questionnaire on policy manifesto administered to selected local councillors and technical officials in Hoima district. 
Table 2. Descriptive statistics on the level of policy manifesto in the Hoima District

\begin{tabular}{lll}
\hline Construct & $\boldsymbol{\mu}$ & SD. \\
Your district screens aggregate policies from interest groups. & 2.89 & 1.291 \\
The civil society in your district competes on the basis of their manifestos for government & 2.88 & 1.513 \\
recognition. & & \\
Civil society publishes their policy positions in the district. & 2.84 & 1.344 \\
Civil society invites influential officials to policy conferences. & 2.22 & 1.305 \\
Citizens have an opportunity to lobby for the policy direction. & 2.99 & 1.284 \\
Average & $\mathbf{2 . 7 6}$ & $\mathbf{1 . 3 4 7}$
\end{tabular}

Legend: $1.00-1.70$ (very low), $1.70-2.40$ (low), 2.40 - 3.10 (moderate), $3.10-3.80$ (high), $3.80-5.00$

(very high)

Source: Primary data.

Table 2 reveals that the study rated four of the five factors as "moderate". For instance, concerning whether "the district screens aggregate policies from interests groups", most of the respondents (28\%) agreed while $18 \%$ strongly disagreed $(\mu=2.89 ; \mathrm{SD}=1.291)$, interpreted as "moderate". As regards whether "civil society in Hoima district competes with on the basis of their manifestos for government recognition", most of the respondents (29\%) strongly disagreed while $21 \%$ agreed $(\mu=2.88 ; \mathrm{SD}=1.513)$, interpreted as "moderate". Regarding whether "civil society publishes their policy positions in the district", most of the respondents $(29 \%)$ agreed while $24 \%$ disagreed $(\mu=2.84 ; \mathrm{SD}=1.344)$, interpreted as "moderate". Furthermore, regarding whether "citizens have an opportunity to lobby for the policy direction", most of the respondents (26\%) disagreed while only $21 \%$ agreed $(\mu=2.99 ; \mathrm{SD}=1.284)$.

The study indicates that all four factors were rated as moderate, suggesting that the study established policy screening, the contribution of civil society and lobbying as fundamental elements in the policy manifesto phase. This implies that policy formulation requires appropriate policy screening, a contribution from civil society, and vigorous lobbying by various citizens. The outcomes agree with the Government of Uganda (1995; Chap. Eleven), giving LGs both executive and legislative powers. For instance, the legal framework devolved power to make development plans that are based on locally determined priorities. The study agreed with the systems model (Pillay, 2019), which presents a set of five critical issues in the policy formulation process, namely: i) policy formulation is a technique used to measure organisational effectiveness through an evaluation of the effect of a programme; ii) policy formulation involves estimating the impact of the policy on the local programmes and projects; iii) policy formulation is a systematic and data-based alternative to intuitive ideas about the effects of policy options used in problem assessment and monitoring as a 'before the view' decision tool; iv) policy formulation, as a technique, puts data to use in deciding about, estimating and measuring the consequences of public policies such as whether any new district should be carved out of an existing district; and v) policy formulation provides maximum ideas with minimal costs about the likely consequences of proposed policies, the actual consequences of the policies in place, and various approaches to be applied to implement or assess them, i.e. cost-benefit analysis.

The different issues relating to policy formulation that were emphasised under the systems model imply that the outcomes of this study which pointed to policy screening, the contribution of civil society and lobbying as fundamental elements in the policy manifesto, were relevant to policy formulation in Hoima district. On the other hand, concerning "how do interest groups compete on the basis of their manifestos for government recognition and action?" the key informants doubted the success of problem identification in Hoima district during the interview, it was noted that:

Interest groups have failed to compete with their manifestos for $L G$ recognition and action since Hoima district has deliberately refused to recognise them as citizens in the policy formulation process. This has left us in a tight spot seeing that we cannot easily assemble the difference between the needs and priorities of the local people in the district. (Member, Hoima DEC, 10/02/2021) 
The doubt captured from the first interview indicates that civil society, one of the engines of local economic development (LED) through effective policy manifestos, had not freely played its part. As a consequence, the level of policy formulation could not be expected to be better in Hoima district. Concerning "the means through which technical officials and local councillors hold consultations regarding the policy formulation process" one interviewee stated:

I have often witnessed and participated in joint consultations between technical officials and local councillors. The most commonly used means of citizen participation has been joint planning and budgeting sessions. When we come together, we see that there is a high level of consultative between the two groups. (Member, District TPC, 15/02/2021)

The study established that one statement was rated as "low" by the respondents, i.e. "civil society invites influential officials to policy conferences". Most of the respondents (41\%) strongly disagreed and only $13 \%$ agreed $(\mu=2.22 ; \mathrm{SD}=1.305)$. The outcome, which is presented in Table 2 , revealed that civil society had not been strong enough to mobilise grassroots people through policy conferences. This outcome further showed that the idea of a participatory policy formulation process earlier emphasised by Lourival and Rose (2020) was never attended to. Overall, the five constructs regarding policy manifesto were rated as "moderate" and given an overall $\mu=2.76=\approx 3$ and overall $\mathrm{SD}=1.347$, which falls under "neutral" on the Likert scale. This outcome implies that the policy manifesto was generally modest in the Hoima district, which suggests that the level of policy formulation through the policy manifesto was still desirable in the district in spite of the downward trend. During the interview, when the key informants were asked about "the major consultative aspects of the policy formulation process in Hoima", they emphasised that:

[t]he major consultative aspects of the policy manifesto process in Hoima mainly alternate around three aspects: recognition and action, policy positions, and influence of government officials to function. (Member, District council, 15/02/2021)

The interviewees' position regarding the policy manifesto in the Hoima district indicated that the citizens recognised the core aspects of the policy manifesto. What remained to be done was consolidating that recognition and action, policy positions, and the influence of government officials to function in the district. The issues raised under the policy manifesto agreed with the national legislation that vested LG councils with full powers, executive and legislative, in their jurisdictions (Government of Uganda, 1995; Chap. Eleven).

\subsection{Policy agenda}

Policy agenda typically concerns "screening of the policy problem"; it is a process by which a specific LG makes its first plan about particular policy problems. A policy agenda involves three core areas: compiling a shortlist of intended government activities, profiling each activity with accompanying justifications, and engaging in vigorous debate. Table 3 illustrates the outcomes generated from the questionnaire that was administered to selected local councillors and technical officials of Hoima district.

Table 3. Descriptive statistics on the degree of policy agenda in the Hoima District

\begin{tabular}{lll}
\hline Constructs & $\boldsymbol{\mu}$ & SD \\
Your district compiles a shortlist of intended government activities. & 2.51 & 1.351 \\
Different citizens engage in compiling the activity shortlist. & 2.50 & 1.233 \\
Your district outlines each government activity with justifications. & 2.29 & 1.309 \\
You engage in vigorous discussions about government activities. & 2.08 & 1.189 \\
You are satisfied with the amount of time allowed for policy discussions. & 2.72 & 1.259 \\
Average & $\mathbf{2 . 1 7}$ & $\mathbf{1 . 2 6 8}$ \\
\hline
\end{tabular}

Legend: 1.00 - 1.70 (very low), 1.70 - 2.40 (low), $2.40-3.10$ (moderate), $3.10-3.80$ (high), $3.80-5.00$ (very high)

Source: Primary data. 
The study established that three of the five constructs concerning policy agenda as "moderate". For instance, regarding whether "the district compiles a shortlist of intended government activities", most of the respondents (30\%) strongly disagreed while only $15 \%$ agreed $(\mu 2.51 ; \mathrm{SD}=1.351)$, interpreted as "moderate". Second, concerning whether "the different citizens engage in compiling the activity shortlist", most of the respondents (32\%) disagreed while just $21 \%$ agreed $(\mu=2.50 ; \mathrm{SD}=1.233)$, interpreted as "moderate". And third, in connection with whether "the amount of time allowed for policy discussions is enough", most of the respondents (42\%) strongly disagreed while a mere $11 \%$ agreed, $(\mu=2.72 ; \mathrm{SD}=1.259)$, interpreted as "moderate". The three outcomes cumulatively implied that compiling of the shortlist, engagement in the compiling activity and duration of policy discussions, were important elements driving the policy agenda in Hoima district. During one of the interviews, regarding "how extensive is the policy problem discussed in the district?" the key informant revealed that:

We often follow the policy guidelines that were set by the ministry and sent to us. Once a problem or issue is identified and a group of people feels that there is a need to address that problem or issue, we do not waste time though we make sure that there is sufficient discussion of all the pertaining issues. (Member, DEC, 18/02/2021)

Table 3 further indicates that only two of the five constructs were rated as "low" by the respondents in the Hoima district. For instance, regarding whether "the district outlines each government activity with justifications", most of the respondents (37\%) agreed while barely $15 \%$ agreed $(\mu=2.29 ; \mathrm{SD}=1.309)$, interpreted as "low". This revealed that citizens took time to study each of the activities within the proposed policy framework. Indeed, during one of the interviews regarding whether "local councillors conduct any research during the policy formulation process" the key informant pointed out that:

We actually do not know how to conduct formal research, but we do some research during the policy formulation process. This is what helps to compile a list of activities with justifications. (Local councillor, 10/02/2021)

As regards whether "citizens engage in vigorous discussions about government activities", most of the respondents $(40 \%)$ agreed while only $16 \%$ strongly disagreed $(\mu=2.08 ; \mathrm{SD}=1.189)$, interpreted as "low". The outcome of the above two factors indicated that the respondents in Hoima were not satisfied with the district's ability to outline each activity with justifications. Therefore, once the district officials failed to provide justification for each of the activities, it might have become hard for them to convince citizens about whether those activities were of principal importance. In addition, the respondents were not satisfied with the level of discussion engaged in by Hoima district in order to allow citizens to be part of the government activities. A study conducted by Aiston, Fo and Law (2020) found that due to prevailing openings in local governments to articulate full guarantee to gender differences, women remained generally marginalised in most local council activities, except at the village level. Although the study by Crook and Manor specifically focussed on women's participation in local councils, the outcomes were a precursor of the level of discussion engaged in by districts in order to allow citizens to be part and parcel of the LG activities.

Overall, the five constructs regarding policy agenda were rated "low" by respondents in Hoima $(\mu=2.17$; $\mathrm{SD}=1.268$ ). The general outcome confirms what the informant mentioned that:

Local councillors in Hoima district rarely conduct any research during the policy formulation process because most of them are either semi-illiterate or consider council work a source of income rather than a dedicated service; this makes most of them participate in policy formulation without any dependable research. (Local councillor, 18/02/2021)

The responses of the above interviewees revealed that once the district has an apathetic group of councillors, the level of the policy agenda will not be as good as expected. As a result, the general policy formulation process in the district will be rendered unsuccessful. Moreover, regarding "how well the district faired in her policy formulation", the interviewees remarked: 
There has been general laxity in the district, with officials failing to do what they ought to have done; this is especially true about the policy agenda in spite of being one of the critical stages in the policy formulation process. (Member DEC, 15/02/2021)

The outcome generated from another interview revealed that citizens in the Hoima district did not have much commitment to pursue a successful policy agenda. Given a non-successful policy agenda, the ultimate policy formulation process was bound to remain unsuccessful.

\subsection{Policy debate}

During policy formulation, the stage "policy debate" involves a broad discussion of various policy problems using formal and informal approaches. Policy debate involves public officials within government departments, interest groups, newspapers, or local citizens. A policy debate frequently generates four main factors: technical data about the nature and level of the policy problem, potential and actual consequences of participation action and inaction, strategies following the problems, and socio-political and economic costs of the policy problem.

Table 4 indicates the outcomes generated from the respondents regarding the degree of policy debate, which was one of the fundamental constructs under policy formulation in Hoima district.

Table 4. Descriptive statistics on the degree of policy debate in Hoima District

\begin{tabular}{lll} 
Constructs & $\boldsymbol{\mu}$ & SD \\
Departmental members discuss the policy problem through seminars. & 2.71 & 1.211 \\
Informal group members engage in the policy proposals. & 2.66 & 1.316 \\
Interest groups take part in seminars concerning the policy debate. & 2.50 & 1.196 \\
Your district allows local citizens to make policy proposals. & 2.46 & 1.295 \\
Your district generates the needed data about the nature and level of the policy problem. & 2.72 & 1.358 \\
Your district provides potential and actual outcomes of proposed policies. & 2.41 & 1.248 \\
Average & $\mathbf{2 . 5 8}$ & $\mathbf{1 . 2 7 1}$ \\
\hline
\end{tabular}

Legend: 1.00 - 1.70 (very low), $1.70-2.40$ (low), 2.40 - 3.10 (moderate), $3.10-3.80$ (high), $3.80-5.00$ (very high)

Source: Primary data.

Table 4 reveals that all the five constructs presented to the respondents during the study were rated as "moderate". The study revealed means ranging between 2.46 and 2.71 and standard deviations ranging between 1.196 and 1.358. First, regarding "departmental members discuss the policy problem through seminars", most of the respondents (29\%) strongly agreed while the least number (6\%) disagreed $(\mu=2.71 ; \mathrm{SD}=1.211)$. Second, concerning whether "informal group members engage in the policy proposals", most of the respondents $(27 \%)$ disagreed while only $11 \%$ strongly agreed $(\mu=2.66$; SD =1.316). Third, regarding whether "interest groups take part in seminars concerning the policy debate", most of the respondents $(32 \%)$ disagreed while only $6 \%$ strongly agreed $(\mu=2.50 ; \mathrm{SD}=1.196)$. Fourth, as regards whether "your district allows local citizens to make policy proposals", most of the respondents $(32 \%)$ agreed, while the least number $(6 \%)$ strongly agreed $(\mu=2.50 ; \mathrm{SD}=1.196)$. Fifth, concerning whether "your district generates the needed data about the nature and level of the policy problem", most of the respondents $(40 \%)$ agreed while barely $6 \%$ strongly disagreed $(\mu=2.72$; $\mathrm{SD}=1.358$ ). And lastly, regarding whether "your district provides potential and actual outcomes of proposed policies", most of the respondents $(42 \%)$ strongly disagreed while the least number $(5 \%)$ agreed $(\mu=2.41 ; \mathrm{SD}=1.248)$.

The study recapped the findings of Ogohi (2018) who noted that informal groups as well as interest groups, local citizens, data on the policy, and projected policy outcomes are critical ingredients of performance in aspects such as the policy debate in LGs. This implies that policy debate was a very important aspect of the policy debate of Hoima district, which required approaching using a multisectoral strategy. The study further established that technical data about the nature and level of the policy problem is equally important. The study supports the views raised by (Hudson, Hunter and Peckham (2019) on policy supported when he noted that policies that appear to be somewhat modest to 
handle and have a compromise necessitate modest support. Moreover, the study reaffirmed that potential and actual consequences of government action and inaction remain fundamental elements of policy debate (McConnel \& Hart, 2019). In addition, the outcomes indicated that strategies of following the problems and the socio-political costs of the policy problem were critical aspects of the policy debate as far as Hoima district was concerned. Overall, policy debate in the Hoima district was rated by the respondents as "moderate" ( $\mu=2.58 ; \mathrm{SD}=1.271)$. These outcomes revealed that policy debate was still considered among citizens in Hoima district and so was the process of policy formulation. This view was supported by the key informants who commented:

Policy problems are discussed by the various organs of the district council, although they are not as extensive as they ought to be, and I think that we as citizens of Hoima need to squarely address this gap. (District TPC Member, 14/02/2021)

This view generated from the interviewee showed that the Hoima district was debating policies at a "thin level", which pointed up the need for it to be stepped up in order to improve the level of policy formulation.

\subsection{Policy decisions}

The final stage, "policy decisions", involves a vigorous search for viable alternatives as the central concern. Usually, policy decisions are translated into programmes and projects for implementation. Table 5 illustrates the outcomes that were generated from the questionnaires administered to selected local councillors and technical officials in the Hoima district.

Table 5. Descriptive statistics on the degree of policy decisions in the Hoima District

$\begin{array}{lll}\text { Constructs } & \boldsymbol{\mu} & \text { SD } \\ \text { You have an adequate opportunity to select from policy options. } & 2.03 & 1.197 \\ \text { You contribute to translating policy decisions into programmes. } & 2.44 & 1.337 \\ \text { Your district conducts a frequent search for alternative policy actions. } & 2.26 & 1.359 \\ \text { You are given the opportunity to propose strategies for district projects. } & 2.21 & 1.259 \\ \text { Your district allocates enough resources for project implementation. } & 2.08 & 1.189 \\ \text { Average } & \mathbf{2 . 2 0} & \mathbf{1 . 2 6 8}\end{array}$

Legend: 1.00 - 1.70 (very low), 1.70 - 2.40 (low), 2.40 - 3.10 (moderate), $3.10-3.80$ (high), $3.80-5.00$ (very high)

Source: Primary data.

The study established that out of the five constructs presented to the respondents, only one had a mean of 2.44 and an SD of 1.337, interpreted as "moderate". The statement sought to determine whether one contributes to translating policy decisions into programmes. The study established that the contribution to translating policy decisions into programmes was significant. In addition, in one of the interviews, a member stated:

The district has an ambitious set of decisions indicating robust changes in both the short term and medium term; most of us take part in decision-making. Nonetheless, several constraints persist mid-way, ranging from financial to personnel resources. (DEC member, 10/02/2021)

The outcome from one of the focus group discussants implies that several members contributed to translating policy decisions into programmes in the Hoima district. However, the process of translating policy decisions into programmes and projects was not as successful as expected, given the financial and personnel limitations which affected the ultimate policy decisions.

The other four constructs on policy decisions were all poorly rated. For instance, regarding whether "you have adequate opportunity to select policy options", most of the respondents (37\%) strongly disagreed while only $8 \%$ agreed $(\mu=2.03 ; \mathrm{SD}=1.197)$. As regards the second statement, regarding whether "the district conducts a frequent search for alternative policy actions", most of the respondents (26\%) disagreed while $11 \%$ agreed $(\mu=2.26 ; \mathrm{SD}=1.35)$. Concerning the third statement, which regarded 
whether "opportunity is given to citizens to propose strategies for district projects", most of the respondents $(30 \%)$ strongly disagreed while $11 \%$ agreed $(\mu=2.21 ; \mathrm{SD}=1.259)$. Concerning the fourth construct, i.e. "the district allocates enough resources for project implementation", most of the respondents $(41 \%)$ strongly disagreed while only $7 \%$ agreed $(\mu=2.08 ; \mathrm{SD}=1.189)$. Each of the four constructs generated an outcome that was interpreted as "low". These outcomes indicated that the decisive policy decisions were not in line with the projected priorities of the citizens in Hoima district, thus supporting the earlier views of McConnel and Hart (2019), who found the contrary. The study established that adequate opportunity, frequent search for policy actions, an opportunity given to citizens, and adequacy of resources are necessary ingredients in policy decisions. On the contrary, the interviewees' perception of "technical officials' conduct in the situational analysis during policy formulation in Hoima" is borne out by the remark that:

Collaboration between technical officials and local councillors in situational analysis during policy decisions has failed to take into consideration knowledge of all the value preferences, policy alternatives and consequences of each policy. (Member District Budget Committee, 12/02/2021)

The observation captured from the interviewees concerning policy decisions indicated that the search for alternative courses of action was not one of the critical concerns in Hoima district. Therefore, translating policy decisions into programmes and projects for implementation remained an obstacle for Hoima district citizens. To get a general picture of how the respondents rated policy decisions in the Hoima district, an average mean for all five policy decisions was computed. The outcome revealed a mean of 2.20 and an SD of 1.268, interpreted as "low". The study established that the majority of the respondents disagreed with the factors concerning policy decisions in the Hoima district. The outcome further showed that the lack of an effective policy decision process contributed to a low level policy formulation in Hoima District.

Table 6 summarises the average means and standard deviations for each of the five constructs under policy formulation in Hoima district.

\begin{tabular}{lll} 
Table 6. Summary of policy formulation in the Hoima District \\
\hline Policy Formulation & Mean & Standard Deviation \\
Problem identification & 2.88 & 1.346 \\
Policy manifesto & 2.76 & 1.347 \\
Policy agenda & 2.17 & 1.268 \\
Policy debate & 2.58 & 1.271 \\
Policy decision & 2.20 & 1.268 \\
Overall & $\mathbf{2 . 5 2}$ & $\mathbf{1 . 3 0 0}$ \\
\hline
\end{tabular}

The general mean for policy formulation in Hoima was rated as "moderate" and generated from all the five constructs, including problem identification $(\mu=2.88 ; \mathrm{SD}=1.346)$, problem manifesto $(\mu=2.76$; $\mathrm{SD}$ $=1.347)$, policy agenda $(\mu=2.17 ; \mathrm{SD}=1.268)$, policy debate $(\mu=2.58 ; \mathrm{SD}=1.271)$ and policy decision $(\mu=2.20 ; \mathrm{SD}=1.268)$. This was so because the overall mean was 2.52 while the overall SD was 1.300 . From the overall outcomes, the study indicated that policy formulation was generally modest in the Hoima district despite the setbacks faced in the phase of policy decision. This view was equally held by Ssonko (2013) in his study on the ability of Uganda to pass a role model test. During one of the interviews, the study participants stressed:

We, as technical officials, have been conducting the situational analysis during policy formulation using the available instruments. For instance, we use the Technical Planning Committee and Departmental Committee fora in order to have effective analysis of the policy formulation situation. (District TPC member, 14/02/2021) 
The ideas underscored by the participant suggests that the district was trying to do what the legal framework stipulates. However, results were either too slow to achieve or were overshadowed by other activities in the district.

The study agreed with the systems model, which calls for an assessment of six consequences, namely: a)the significant dimensions of the environment that generate demands upon the political system; $b$ ) the major characteristics of the political system that enable it to transform demands into public policy and to preserve itself over time; c) the effect of the environmental inputs on the character of the political system; d) the consequence of the characteristics of the political system for the content of public policy; e) the outcome of environmental inputs on the content of public policy; and f) the result of public policy, through feedback, the environment and the character of the political system. Although the systems model did not specifically address the issues in the Hoima district, its relevance is convincing as noted by Hick, Bajzek and Faustmann (2019), especially when seen from the five stages presented in the policy formulation process.

Therefore, the systems model needed to be assessed in relation to the five stages of policy formulation: problem identification, policy manifesto, policy agenda, policy debate, and policy decisions in the Hoima district. Nonetheless, according to the systems model, the study established that 'supports' should include both the immaterial and material inputs of a system. Such inputs involve obeying laws or respecting the national flag, which would then constitute the psychological and material resources of the system. Analytically, obeying the laws would call for three basic considerations: democracy in view of the fact that those laws were made by and adopted as a result of a popular majority; the rule of law which is not discriminatory; and citizens who have respect and faith in the laws. According to Pincione (2019), the considerations mentioned above would require action research into the real issues concerning policy formulation. Indeed, the study participants commented:

There are very few achievements that have been registered regarding conducting action research on the policy under formulation. When some of us try to determine why the condition is like that, we have always been told that there is no budgetary provision to cater to research since we operate a deficit budget. (Member district TPC, 15/02/2021)

The outcome from the key informants in the interview indicates that "research" was one of the important issues in policy formulation, but there were several limitations among the citizens in Hoima district. The argument was further supported by other study participants who stated:

In order for someone to carry out reasonable research, that person needs to have the knowledge and skills in doing so; it is, therefore, wrong to assume that our less educated councillors will ever do so, not at this time. (DEC member, 15/02/2021)

The view presented in the extract shows that local councillors, who would have loved to conduct research, were largely limited in terms of knowledge and skills. Therefore, lack of research in Hoima district was a symptom of a shortage of knowledge and skills among citizens.

\section{Conclusion}

This study set out to assess the level of policy formulation using a system model in Hoima district, mid-western Uganda. The findings suggest the significance of each of the five stages in policy formulation, namely, problem identification, policy manifesto, policy agenda, policy debate, and policy decisions. It is inferred here that local governments in Uganda pay more attention to the quality of each of the stages in policy formulation since the quality of the foundation will determine the quality of the final product during policy implementation and evaluation. Therefore, every stakeholder, elected or appointed, needs to play their part in realising this goal. 


\section{Limitation and study forward}

This study was conducted in one local government of Hoima and so the outcomes may not be generalised for Uganda.

\section{Acknowledgement}

The authors wish to acknowledge the cooperation of every respondent in the study.

\section{References}

Abugre, BJ. (2020). The moderating role of affective interpersonal conflict on managerial decisionmaking and organisational performance in private sector organisations: a study of Ghana. Journal of African business, 21(1). 20-41. Doi: 10.1080/15228916.2019.1596707

Aiston, JS., Fo, KC., and Law, WW. (2020). Interrogating strategies and policies to advocate women in academic leadership: the case of Hong Kong. Journal of higher education policy and management, 42(3). 347-64. Doi: 10.1080/1360080X.2020.1753393

Assad, N.B.D., and Spiegel, T. (2020). Improving emergency department resource planning: a multiple case study. Health systems, 9(1). 2-30. Doi: 10.1080/20476965.2019.1680260

Awin, N. (2019). Role of policy makers in ensuring access to adequate treatment for achieving patient and family quality of life: experience in Mallaysia. Haemoglobin, 43(6). 320. Doi: $10.1080 / 03630269.2020 .1718327$

Bartels, PRK., Wagenaar, H., and Li, Y. (2020). Introduction: towards deliberative policy analysis 2.0. Policy studies, 41(4). 295-306. Doi: 10.1080/01442872.2020.1772219

Bhuiyan, S., and Farazmand, A. (2020). Society and public policy in the Middle East and North Africa. International journal of public administration, 43(5). 373-7. Doi: $\underline{10.1080 / 01900692.2019 .1707353}$

Boosabong, P., and Chamchong, P. (2019). The practice of deliberate policy analysis in the context of political and cultural challenges: lessons from Thailand. Policy studies, 40(5). 476-91. Doi: $10.1080 / 01442872.2019 .1618815$

Burke, S. (2019). Re-imaging the local in national cultural policy formulation - the case of the Anglophone Caribbean. Cultural trends, 28(4). 269-80. Doi: 10.1080/09548963.2019.1644782

Capano, G., Howlett, M., and Ramesh, M. (2015). Bringing governments back in: governance and governing in comparative policy analysis. Journal of comparative policy analysis: research and practice, 17(4). 311-21. Doi: 10.1080/13876988.2015.1031977

Carbone, D., and Farina, F. (2020). Women in the local political system in Italy. A longitudinal perspective. Contemporary Italian politics, 12(3). 314-28. Doi: 10.1080/23248823.2020.1793078

Chijioke-Oforji, C. (2019). Banking law and regulation. The law teacher, 53(4). 551-3. Doi: 10.1080/03069400.2019.1636521

Durrer, V., Gilmore, A., and Stevenson, D. (2019). Arts councils, policy-making and 'the local'. Cultural trends, 28(4). 317-31. Doi: 10.1080/09548963.2019.1644795

Farell, L., Bourgeouis-Law, G., Buydens, S., and Regehr, G. (2019). Your goals, my goals, our goals: the complexity of coconstructing goals with learners in medical education. Teaching and learning medicine, 31(4). 370-7. Doi: 10.1080/10401334.2019.1576526

Frisk, S., and Gillette, BM. (2019). Sweden's Burka Ban: policy proposals, problematisations, and the production of Swedishness. NORA-Nordic journal of feminist and gender research, 27(4). 27184. Doi: $10.1080 / 08038740.2019 .1668847$

Government of Uganda. (1995). The national constitution. Uganda printing press corporation, Entebbe.

Grossmann-Wirth, V. (2019). What monetary policy operational frameworks in the new financial environment? A comparison of the US fed and the euro system perspectives, 2007-2019. International journal of political economy, 48(4). 336-52. Doi: $\underline{10.1080 / 08911916.2019 .1693162}$

Hardy, I., Jakhelln, R., and Smit, B. (2020). The policies and politics of teachers' initial learning: the complexity of national initial teacher education policies. Teacher education. Doi: $10.1080 / 10476210.2020 .1729115$ 
Harrison, J., Chapleau, A., Schell, M., Vaughan, V., and Colzin, C. (2020). Leveraging technology in field education of digital natives: using goal attainment scaling. Scaling, social work education, 39(1). 60-70. Doi: 10.1080/02615479.2019.1642318

He, JA., Ratigan, K., and Qian, J. (2020). Attitudinal feedback towards sub-Saharan social policy: a comparison of popular support for social health insurance in urban China. Journal of comparative policy analysis: research and practice. Doi: 10.1080/13876988.2020.1780126

Hick, H., Bajzek, M., and Faustmann, C. (2019). Definition of a system model for model-based development. SN application science, 1. 1074. Accessed $6^{\text {th }}$ May 2021: https://doi.org/10.1007/s42452-019-1069-0

Horodnic, AI., and Williams, CC. (2019). Tackling undeclared work in the European Union: beyond the rational economic actor approach. Policy studies, doi: 10.1080/01442872.2019.1649384

Hudson, B., Hunter, D., and Peckham, S. (2019). Policy failure and the policy-implementation gap: can policy support programs help? Policy design and practice, 2(1). 1-14. Doi: 10.1080/25741292.2018.1540378

Krejcie, V.R., and Morgan, W.D. (1970). Determining sample size for research activities. Educational and psychological measurement, 30. 607-10.

Kuttig, J. (2020). Posters, politics and power: mediated materialisation of public authority in Bangladesh party politics, south Asia. Journal of South Asian studies, 43(4). 632-57. Doi: $10.1080 / 00856401.2020 .1767901$

Lourival, I., and Rose, N. (2020). From Nar Nar Goon to Koo Wee Rup: can participatory food policy making processes contribute to healthier and fairer food systems in the Australian municipal context? A case study from Cardinia shire, Melbourne. Journal of hunger \& environmental nutrition. Doi: 10.1080/19320248.2020.1782797

McConnell, A., and Hart, P. (2019). Inaction and public policy: understanding why policy-makers 'do nothing'. Policy sciences, 52. 645-61.

Mortati, M. (2019). The nexus between design and policy: strong, weak, and non-design spaces in policy formulation. The design journal, 22(6). 775-92. Doi: $10.1080 / 14606925.2019 .1651599$

Musenze, AI., and Sifuna, TM. (2020). Development and validation of a total quality management model for Uganda's local governments. Cogent business \& management, 7(1). Doi: $10.1080 / 23311975.2020 .1767996$

Mwesigwa, D., and Mubangizi, BC. (2015). Citizen Participation and policy formulation: A study of bottom-up, top-bottom, and horizontal scenarios in local councils in western Uganda. Journal of Administratio Publica. 23(4). 13-29.

Native, S., Santoro, M., Giuliani, G., and Mazzetti, P. (2020). Towards a knowledge base to support global change policy goals. International journal of digital earth, 13(2). 188-216, doi: 10.1080/17538947.2018.1559367

Ng, B., Mohamad, F.Z., Chandran, VGR., and Noor, MHN. (2019). Public policy interventions for grassroots innovations: are we getting it right? Asian journal of technology innovation, 27(3). 338-58. Doi: 10.1080/19761597.2019.1678392

Ogohi, DC., (2018). Impact of informal groups on organisational performance. International journal of scientific research and management (IJSRM), 6(9). 686-94.

Pan, X., Li, M., Xu, H., Guo, S., Guo, R., and Lee, TC. (2020). Simulation on the effectiveness of carbon emission trading policy: a system dynamics approach. Journal of the operational research society. Doi: 10.1080/01605682.2020.1740623

Panday, K.B., and Chowdhury, S. (2020). Responsiveness of local government officials: insights and lessons from participatory planning and budgeting. Asia pacific journal of public administration, 42(2). 132-51. Doi: 10.1080/23276665.2020.1742753

Pillay, LA. (2019). The minimum age of criminal responsibility, international variation, and the dual systems model in neurodevelopment. Journal of child \& adolescent mental health, 31(3). 22434. Doi: $10.2989 / 17280583.2019 .1692851$

Pincione, G. (2019). 'Rule of law: theoretical perspectives'. In: Sellers, M., Kirste, S. (eds.) Encyclopaedia of the philosophy of law and social philosophy. Springer, Dordrecht. Accessed $6^{\text {th }}$ May 2021: https://doi.org/10.1007/978-94-007-6730-0_135-1 
Reed, R., Curtis, C., and Lovrich Jr. PN. (2020). Does democracy entail an obligation to make rational policy decisions? The muddling through vs. bounded rationality debate through a Lockean and Madisonian lens. Public integrity, 22(4). 316-29. Doi: 10.1080/10999922.2018.1518557

Romanawski, HM., Sadiq, H., Abu-Tineh, MA., Ndoye, A., and Aql, M. (2019). The skills and knowledge needed for principals in Qatar's independent schools: policy makers', principals" and teachers' perspectives. International journal of leadership in education, 22(6). 749-73. Doi: $10.1080 / 13603124.2018 .1508751$

Ruckert, A., Labonte, R., and Lencucha, R. (2019). Health in Canadian foreign policy: the role of norms and security interests. Canadian foreign policy journal, 25(3). 325-41. Doi: $\underline{10.1080 / 11926422.2019 .1642216}$

Saraithong, W., and Chancharoenchai, K. (2019). The micro-determinants of public policy: a case of Thailand's trade policy. International journal of public administration, 42(13). 1135-44. Doi: 10.1080/01900692.2019.1575855

Saxon, J., and Snow, D. (2020). A rational agent model for the spatial accessibility of primary healthcare. Annals of the American association of geographers, 110(1). 205-22. Doi: $10.1080 / 24694452.2019 .1629870$

Schmidt, MN. (2020). Late bloomer? Agricultural policy integration and coordination patterns in climate policies. Journal of European public policy, 27(6). 893-911. Doi: $10.1080 / 13501763.2019 .1617334$

Schulz, M. (2020). Uncertain preferences in rational decision. Inquiry, 63(6). 605-27. Doi: 10.1080/0020174X.2020.1758767

Siverbo, S., Cäker, M., and Åkesson, J. (2019). Conceptualising dysfunctional consequences of performance measurement in the public sector. Public management review, 21(12). 1801-23. Doi: $10.1080 / 14719037.2019 .1577906$

Spéder, Z., Murinkó, L., and Oláh, L. (2020). Cash support vs. tax incenrives: the differential impact of policy interventions on third births in contemporary Hungary. Population studies, 74(1). 3954. Doi: $10.1080 / 00324728.2019 .1694165$

Ssonko, WKD. (2013). Decentralisation and development: can Uganda now pass the test of being a role model? Commonwealth journal of local governance, 13/14. 30-45.

Stark, A., and Head, B. (2019). Institutional amnesia and public policy. Journal of European public policy, 26(10). 1521-39. Doi: 10.1080/13501763.2018.1535612

Vercalsteren, A., Christis, M., Geerken, T., and Van der Linden, A. (2020). Policy needs (to be) covered by static environmentally extended input-output analyses. Economic systems research, 32(1). 121-44. Doi: 10.1080/09535314.2019.1644994

Vesely, A. (2020). Policy formulation redesigned: anew understanding of policy design and its implications for instruction. Teaching public administration, 38(3). 213-32. Accessed $2^{\text {nd }}$ May 2021: https://doi.org/10.1177/0144739420901729

Violet, B., Scelles, N., and Ferrand, A. (2020). The engagement of actors during the formulation of a national federation sport policy: an analysis within the French rugby union. International journal of sport policy and politics, 12(1). 49-71. Doi: 10.1080/19406940.2019.1634621

Wanders, HKF., Dijkstra, BA., Maslowski, R., Van der Veen, I., and Amnå, E. (2020). The role of teachers, parents, and friends in developing adolescents" societal interest. Scandinavian journal of educational research. Doi: 10.1080/00313831.2020.1754901. 